\title{
Study of the Control of Geometric Pattern Using Digital Algorithm (with Focus on Analysis and Application of the Islamic Star Pattern)
}

\author{
Jin-Young Lee, ${ }^{1}$ Sung-Wook Kim, ${ }^{2}$ and You-Chang Jeon ${ }^{2}$ \\ ${ }^{1}$ aDLab+, Suwon-si 16499, Republic of Korea \\ ${ }^{2}$ Department of Architecture, Ajou University, Suwon-si 16499, Republic of Korea \\ Correspondence should be addressed to Sung-Wook Kim; sungkim@ajou.ac.kr
}

Received 1 May 2015; Accepted 27 July 2015

Academic Editor: Antônio G. B. de Lima

Copyright (c) 2015 Jin-Young Lee et al. This is an open access article distributed under the Creative Commons Attribution License, which permits unrestricted use, distribution, and reproduction in any medium, provided the original work is properly cited.

\begin{abstract}
This paper presents a study to analyze and modify the Islamic star pattern using digital algorithm, introducing a method to efficiently modify and control classical geometric patterns through experiments and applications of computer algorithms. This will help to overcome the gap between the closeness of classical geometric patterns and the influx of design by digital technology and to lay out a foundation for efficiency and flexibility in developing future designs and material fabrication by promoting better understanding of the various methods for controlling geometric patterns.
\end{abstract}

\section{Introduction}

With the advance of digital technology, the development of surfaces in modern structures enjoys an unprecedented freedom of expression. The various ability of computer programs, in tune with the will of designers to discover a new design, accelerates the speed of "limitless" design through proliferation, modification, and trajectory tracking. The rapid development of computer technology results in a tendency to perform unpredictable calculations with the computer using an algorithm beyond the control of the artist. The development of manufacturing technology has also enabled the construction of various experimental shapes, which provides a good justification as meaningful construction work. These phenomena try to differentiate themselves from the rules of classical geometry by using terminologies such as "Digital Geometry" and "Digital Materiality." To counter this rapid trend, some architects severely limit the role of the computer, refuse designs made by digital programs, and instead produce designs based on the tradition and history of the sense of geometry. This study will focus on the disparity of such an extreme position regarding the use of computer algorithms in design. The purpose of this study is to identify a connection point of classic geometry and algorithmic design. In other words, to overcome the closeness of classic patterns through studies on the patterns produced by designers and also overcome the influx of design by digital technology, the objective of this study is to introduce a method to efficiently modify and control classical geometric patterns through experiments and applications of computer algorithms.

\section{Methods}

As the analysis object of this study, we used the Islamic star pattern. Specifically, this study selected the 4.8 .8 pattern among the modified star pattern examples used in Hankin's method. For analysis and experiment control of this pattern, we utilized "Grasshopper" and "Rhinoscript," which are plugins for the Rhinoceros program by Robert McNeel and Associates, and "Processing" developed by Ben Fry and Casey Reas. The purpose of the study is presented in Section 1 . The study method is explained in Section 2. Tessellation, Islamic art patterns, and algorithm designs are presented in Section 3. The control methods using the analysis and algorithm of Islamic star patterns are introduced in Section 4: 

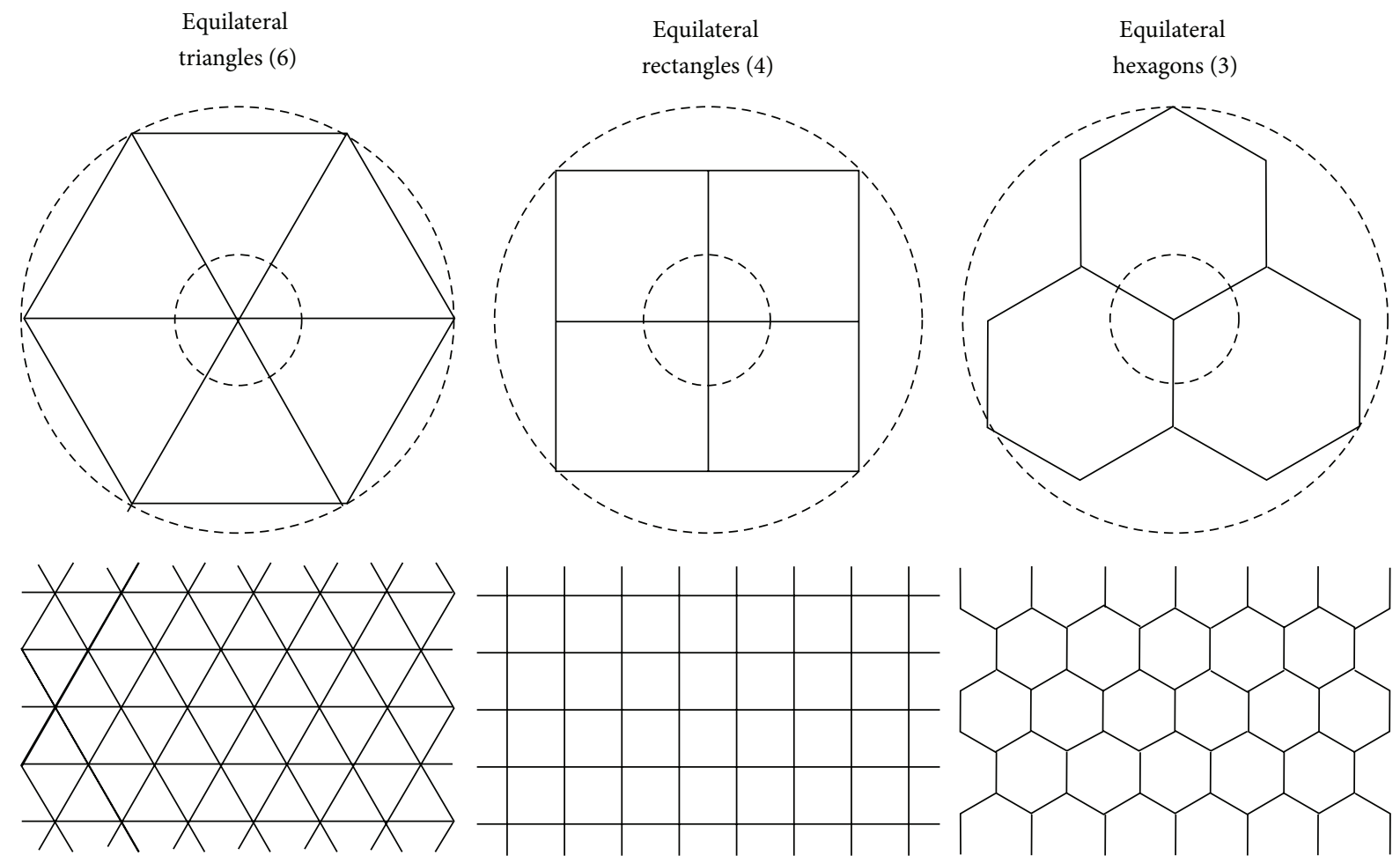

FIGURE 1: Basic formation and combination formula of a tessellation.

(a) the side-splitting method and (b) the single module expansion method. Various experiments to identify the points of intersection are also discussed. Based on these, we will evaluate the potential for modification and convenience of control. This will be summarized in Section 5 .

\section{Tessellation and Algorithm Design}

3.1. Geometric Concept of Tessellation. "Tessellation" can be defined as a pattern of more than one shape which completely covers a certain plane. The regular splitting method of a plane is a method which leaves no gaps by using a certain shape, completely fills out the space without overlapping, and does not allow for overlapping of shapes or gaps [1]. Tessellation is typically composed of closed shapes or closed curves, and the simplest kind of closed curve is a polygon. It is possible to develop a polygon into a tessellation composed of complex shapes. First of all, all kinds of triangles and rectangles can form a tessellation. This is because the sums of their internal angles are $180^{\circ}$ and $360^{\circ}$, respectively [2]. With a combination of 6 equilateral triangles, 4 equilateral rectangles. and 3 equilateral hexagons, we can create a polygon with the total internal angle of $360^{\circ}$. This is the basic formation and combination formula of a tessellation, which has the internal angle of the focal point of $360^{\circ}$ (Figure 1) [3].

If the range of an equilateral polygon is narrowed as in Figure 1, a tessellation can be formed with only three types of polygons: equilateral triangles, equilateral rectangles, and equilateral hexagons. Mathematicians discovered 21 kinds of equilateral polygon combinations which fill up space based on one point at the center (Figure 2) [2].

The patterns which appear on the Islamic buildings and tiles of the Middle Ages started from simple designs and developed into complex designs with mathematical symmetry over centuries. These complex patterns were modified by the strapwalk method (Figure 3) [4] using circles and rectangles in overlapping lattice patterns and were further improved to produce more complicated forms of symmetric patterns. The typical example of tessellation is the complex geometric patterns that Moors and Arabs used to decorate their architecture.

Such Islamic patterns have had great influence on modern artists (Figures 4 and 5). Among them, there are Op artists such as Victor Vasarely and Bridget Riley and print artist M.C. Escher [2].

3.2. Understanding of Algorithm Design. An algorithm is a group of well-defined rules and a finite number of steps used to solve a mathematical problem. It is a set of welldefined rules and commands in a finite number, and it can solve a problem by applying its limited rules [5]. Since an algorithm creates a unit through calculation and forms a pattern, it is opposed to a design which is dependent on heuristic knowledge and inspiration. Nevertheless, the reason why complex calculations and mathematical algorithms are used in designing or creating a pattern is that a design which is created through a calculation process is more effective than one arbitrarily created by an architect in pursuit of freedom 

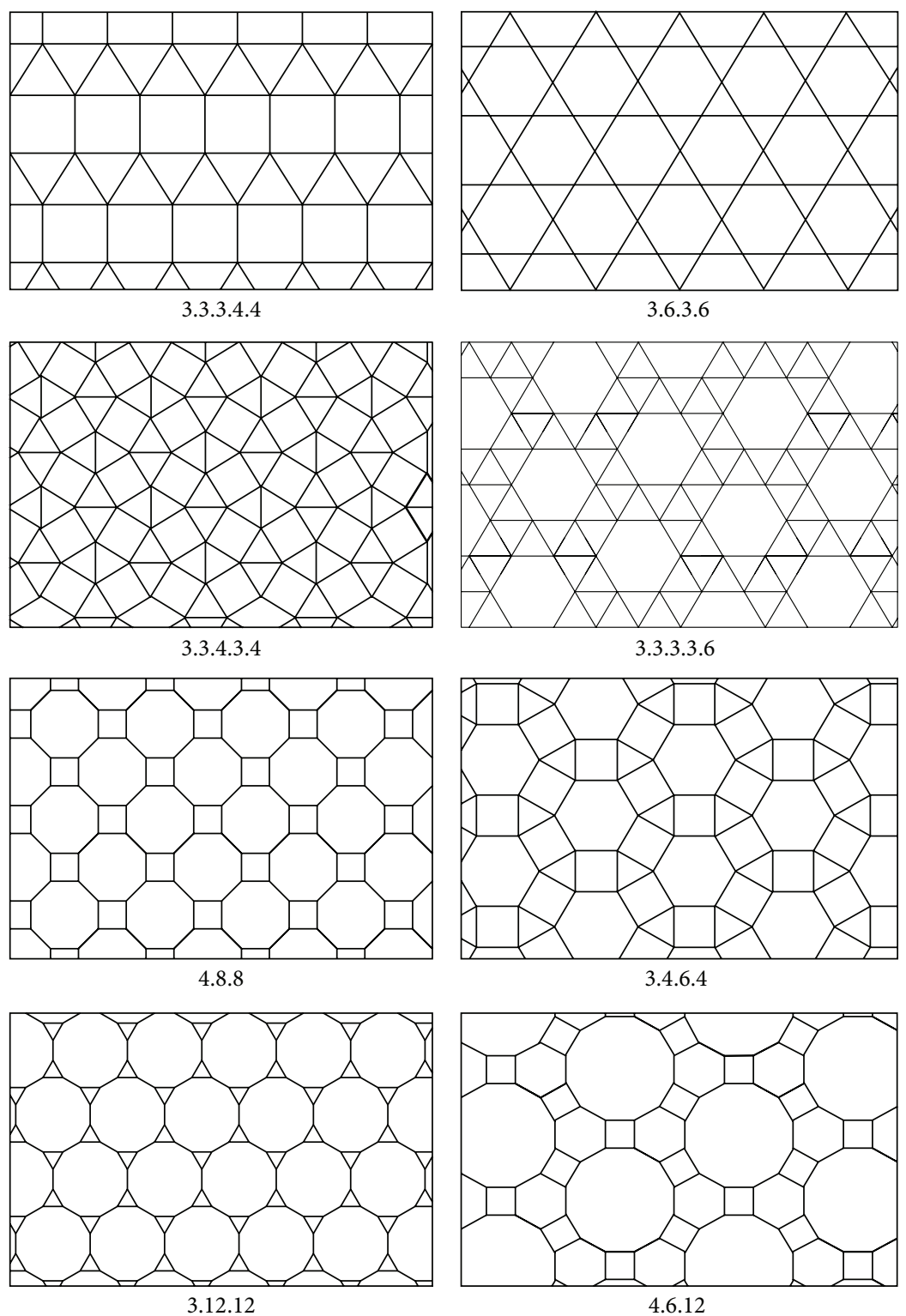

FIgURE 2: Equilateral polygon combinations.

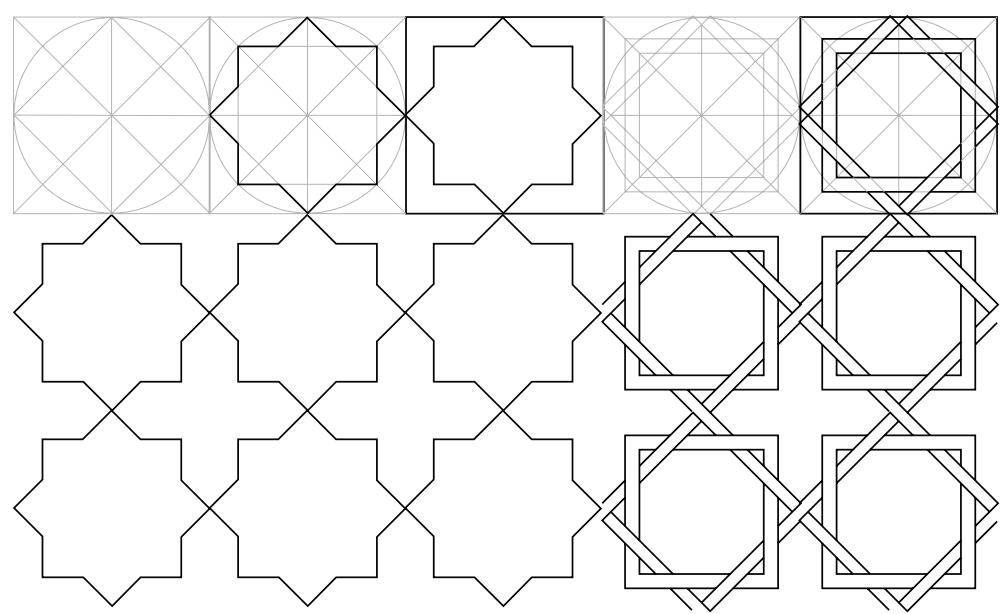

FIGURE 3: Islamic strapwork. 


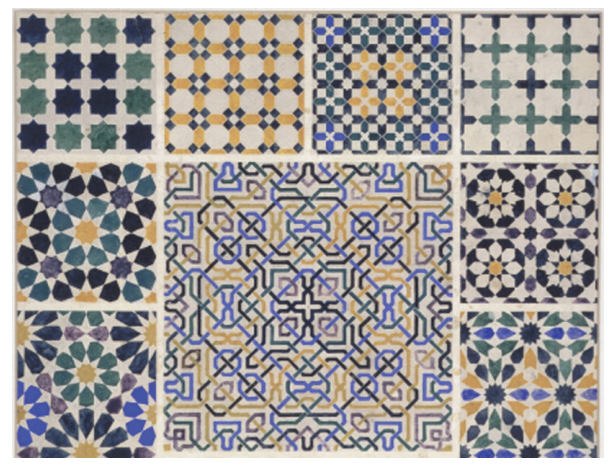

Figure 4: Owen Jones, 1856.
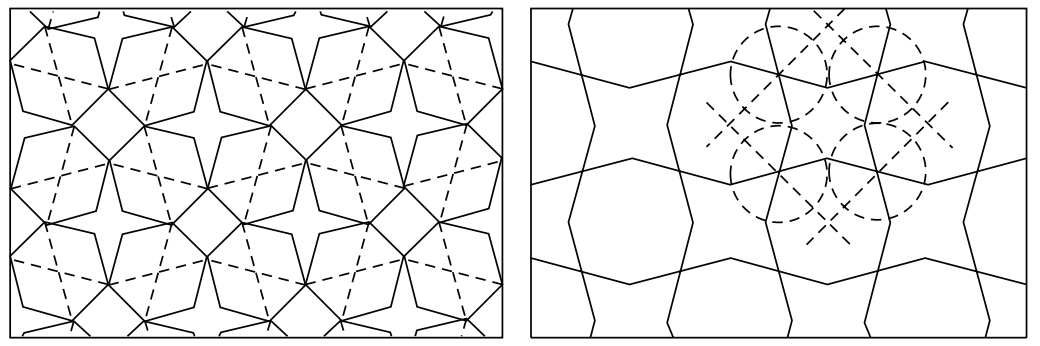

Figure 5: Arabic pattern development (Lewis F. Day).

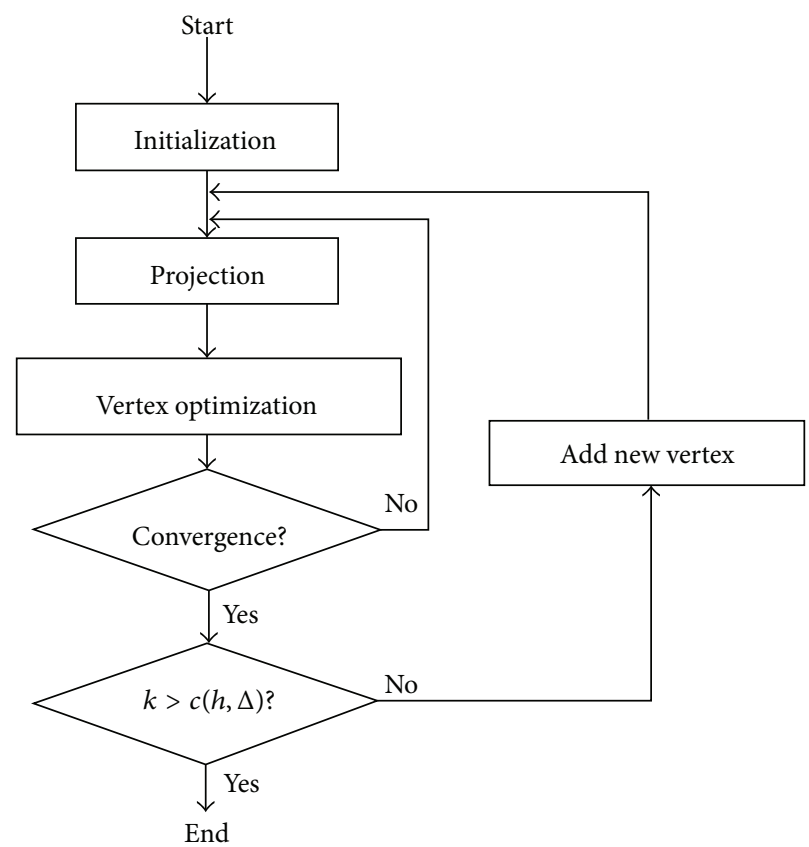

FIGURE 6: Algorithm.
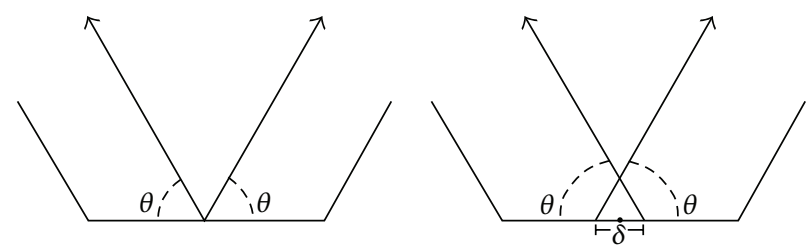

FIGURE 7: Hankin's pattern developing process. 

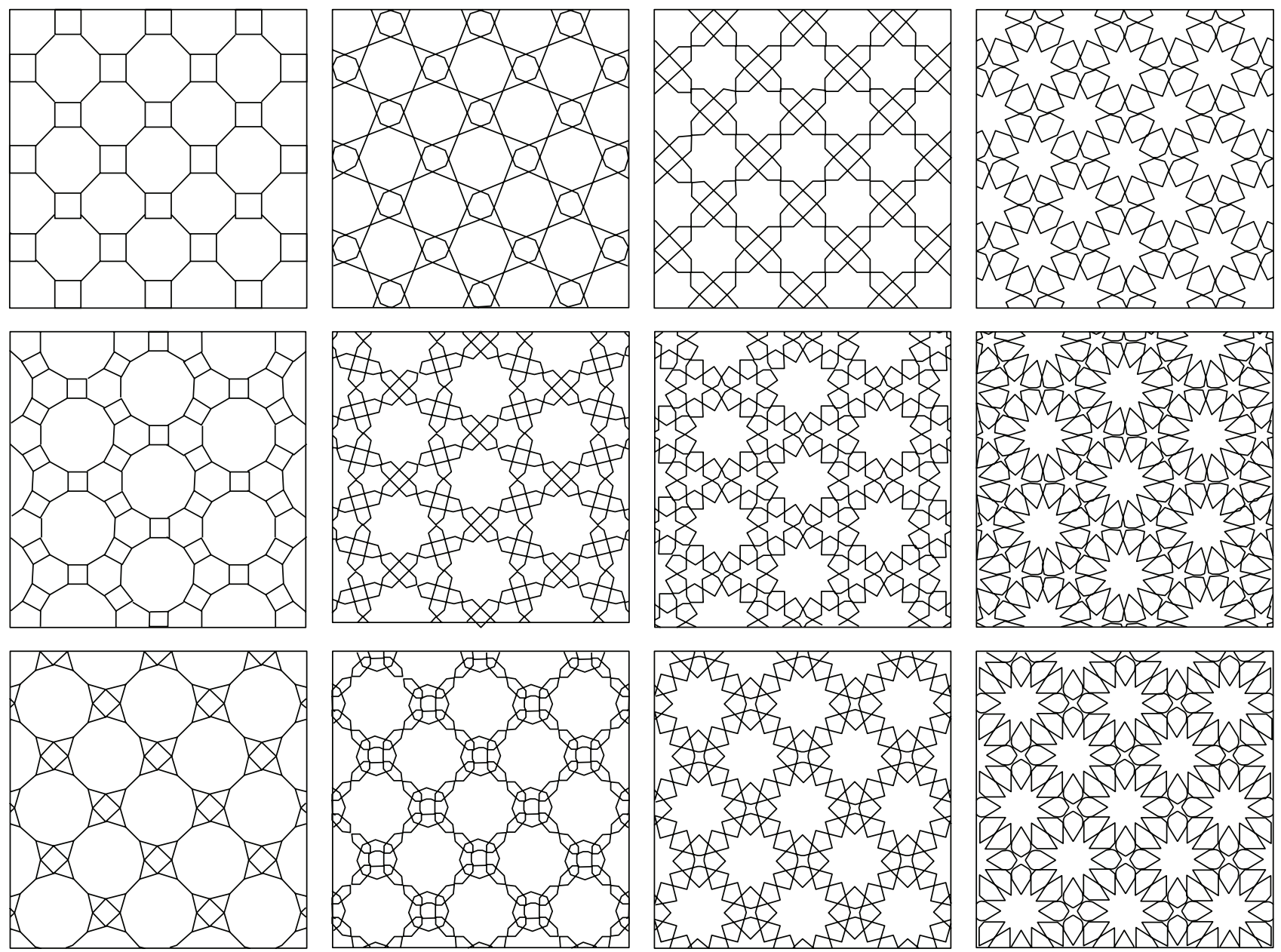

FIGURE 8: Variations of patterns using Hankin's method (Craig S. Kaplan).

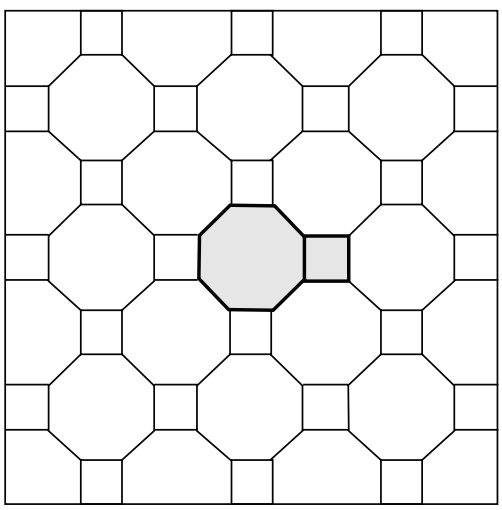

FIgURE 9: Unit module.

of expression and is detached from the real structure [6]. The design process using an algorithm does not appear only in modern society. For centuries from the past to the present, architects have made attempts at design by taking advantage of mathematics as part of an effort to converge mathematics with construction. With the digital tools of modern society, modern mathematical algorithms are used not only in

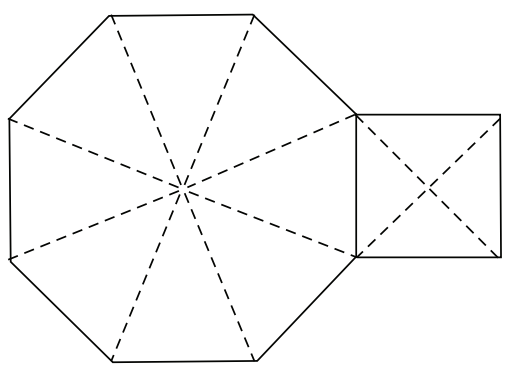

FIGURE 10: 4.8.8 combination.

the design of cars and ships but also in various fields such as computing design and media arts. Also, mathematical algorithms produce results with variables depending on the situation and develop shapes in accordance with the rules of a mathematical formula [7]. Therefore, it is necessary to understand the function of mathematical formulas in order to embody and express shapes based on rules in the process. Consequently, the application of mathematical formulas in construction design can be effectively used to control design by utilizing computing technology in tune 


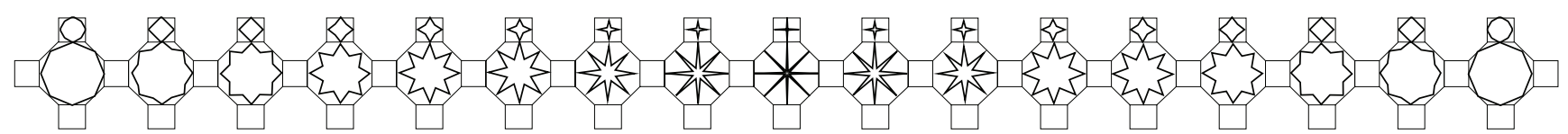

FIGURE 11: Transformation of 4.8 .8 combination.

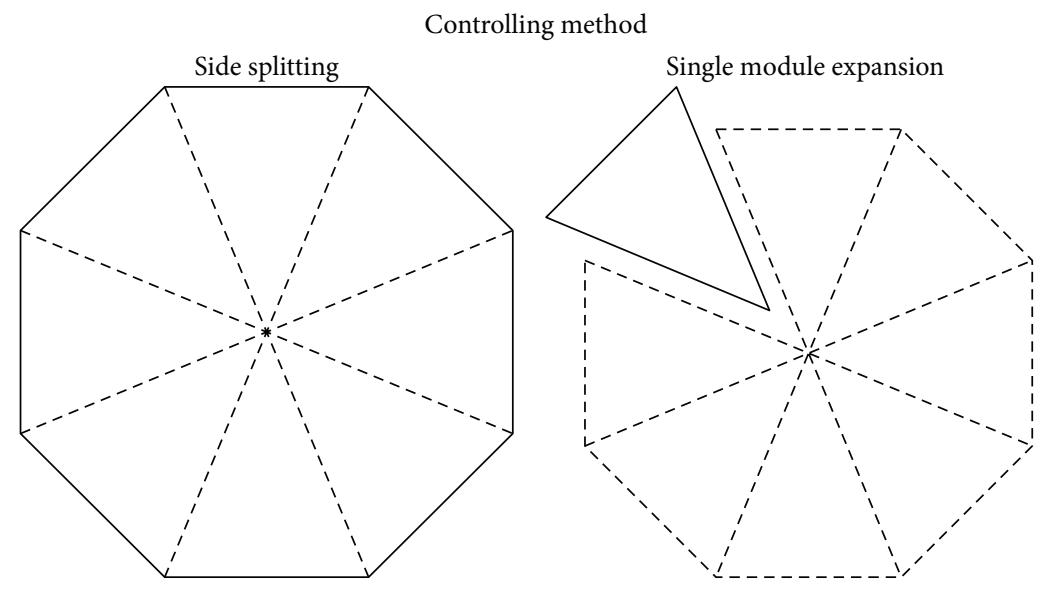

FIGURE 12: Types of controlling method.

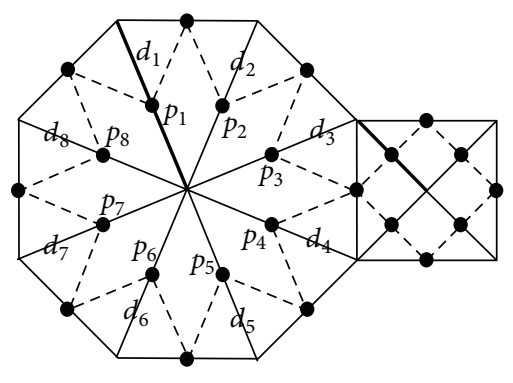

Figure 13: Point on segment control diagram (Type A).

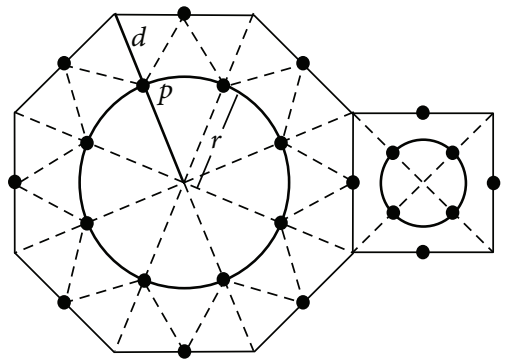

FIGURE 14: Radius control diagram (Type B).

with modern society, and we can implement modification processes through algorithm steps (Figure 6) [8].

\section{Analysis of Islamic Pattern Using Digital Algorithm}

4.1. Outline of Islamic Pattern Design. The Islamic star pattern using geometric figures is one of the world's greatest ornament design traditions. Its expansion including architectural

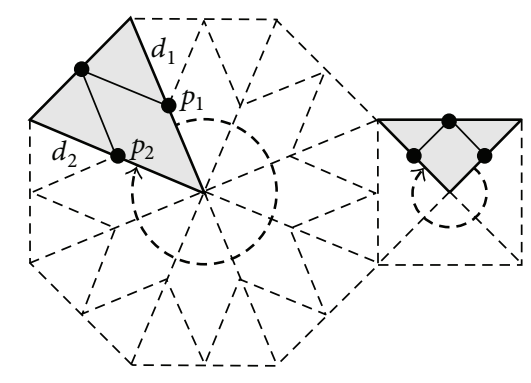

FIgURE 15: Point on segment control diagram (Type C).

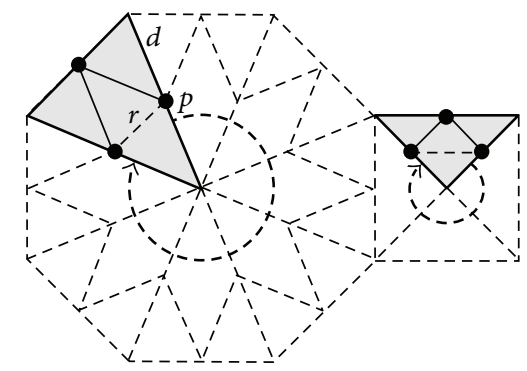

FIGURE 16: Side on segment control diagram (Type D). application significantly grew in the Middle East and Central Asia [9]. The Islamic star pattern expresses the conversion, symmetry, balance, and uniqueness of harmonious mathematics. Islamic art favored the proportional geometry as a sacred art form [10]. The experiment of geometric pattern designs using digital algorithms was conducted to find an effective control method to modify geometric patterns through Grasshopper, a mathematical algorithm-based program that uses parameters, with the goal of learning 


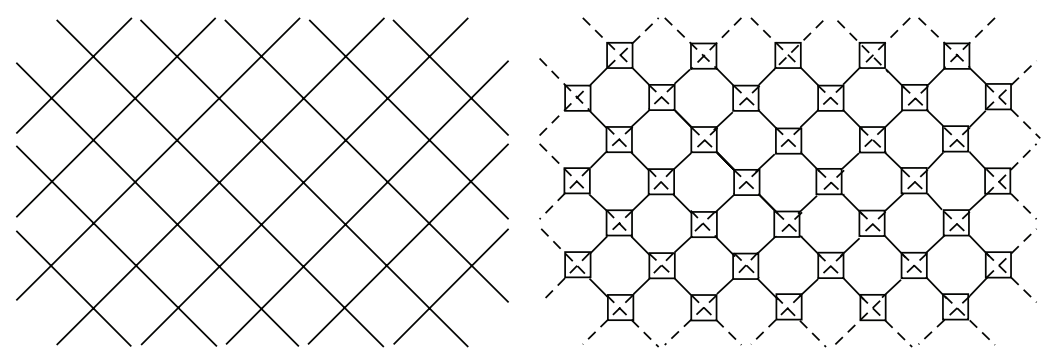

FIGURE 17: Basic geometry from diagrid.

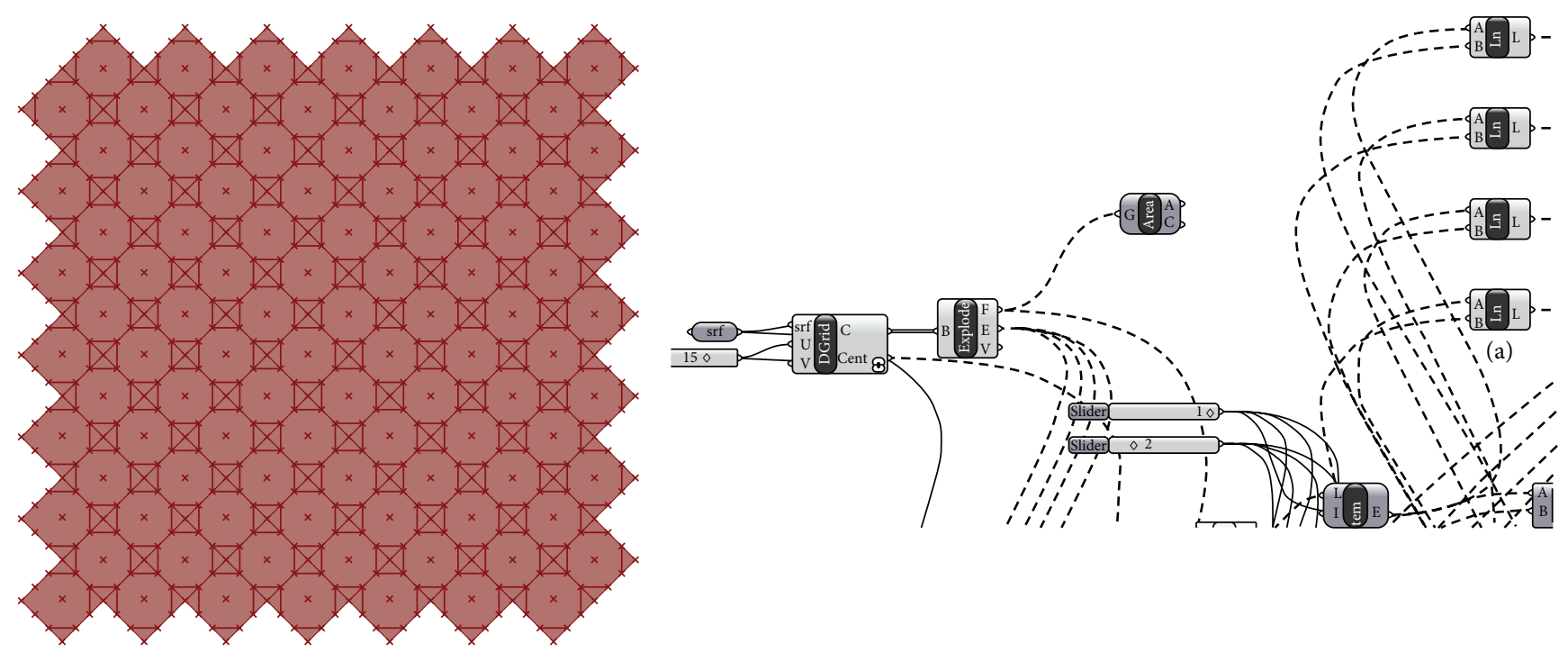

FIGURE 18: Algorithmic formula.

about the formation methods of Islamic star patterns through various shape modifications. In the tiling-based approach of Islamic star patterns, the polygons-in-contact method of E. $H$. Hankin set a milestone. In his paper, he offered a great starting point for an approach to creating Islamic star patterns and provided various examples of pattern formation through Hankin's method (Figures 7 and 8) [11].

4.2. Analysis. As mentioned in Section 3, we will focus on tessellations, which are composed of combinations of multiple unilateral polygons based on basic polygons. Among them, we try to analyze the modification process of geometric figures using the 4.8.8 combination, a basic combination used in Hankin's method, and explore different types of design modification processes using the digital algorithm program Grasshopper. The 4.8 .8 combination is a pattern made up of rectangles and octagons (Figure 9). The unit modules of these octagons and rectangles are made of triangles of certain shapes (Figure 10).

According to Hankin's method, the shape of stars can transform with a change in the angle of the sides of each basic geometric figure (Figure 11). Through a mathematical algorithm that will be analyzed in this study, control methods to create various shapes of geometric figures through mathematical algorithms can be divided into two types: the sidesplitting method and the single module expansion method (Figure 12). If we delve into the side-splitting method, it can be further divided into two types: the point on segment control method (Figure 13) and the radius control method (Figure 14). The single module expansion method can be divided into the point on segment control method (Figure 15) and the line on segment control method (Figure 16).

4.3. Formation of Basic Geometric Figures. To create a simple 4.8.8 geometric figure on a plane, we have to split sides first. For the formation of geometric 4.8.8 figures, we have to start with a plane with a rectangular grid system (Figure 17).

An algorithm formula can be used to create the surface of a rectangle (Figure 10). Entire surface is split into rectangles with a single basic module. Each side of a unit module rectangle is divided into three divisions. If the first point of a side divided into three is connected with the second point of the opposing side, a geometric 4.8.8 figure is created (Figure 18). 
Side-splitting control method

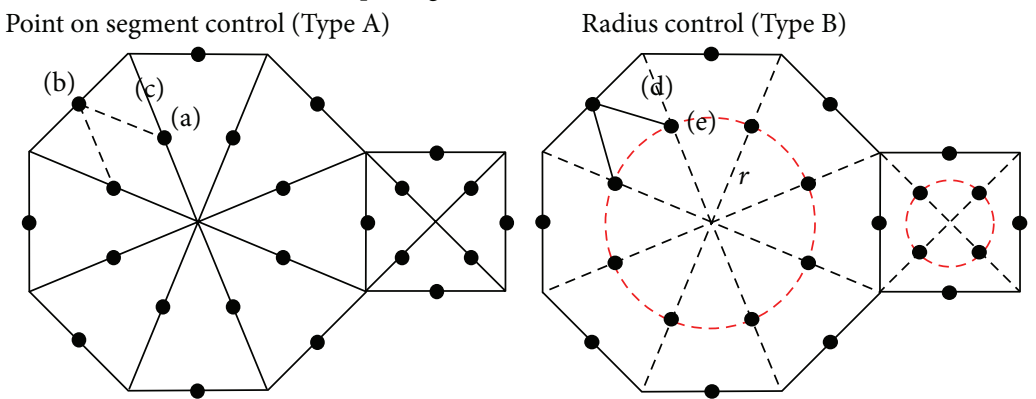

FIGURE 19: Side-splitting control method diagram.

Type A-1

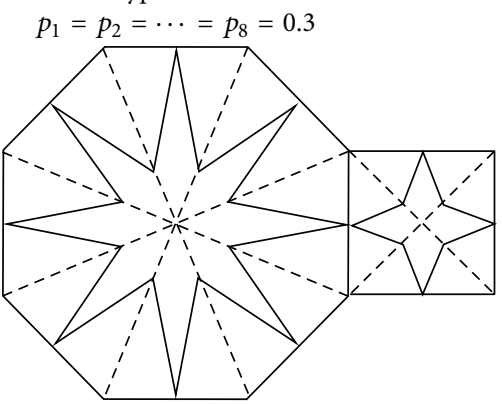

Type A-2

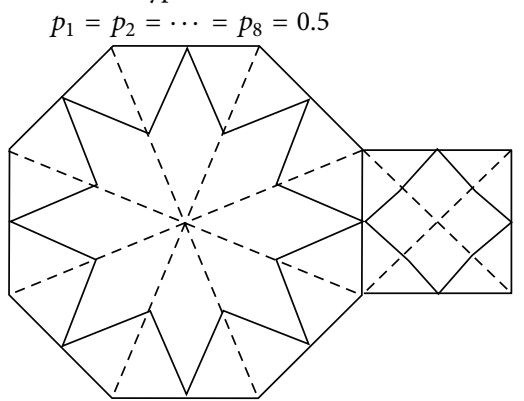

Type A-3

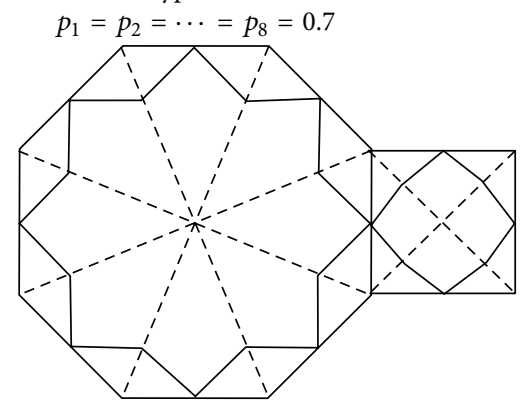

FIgURE 20: Examples of basic variations: Type A.
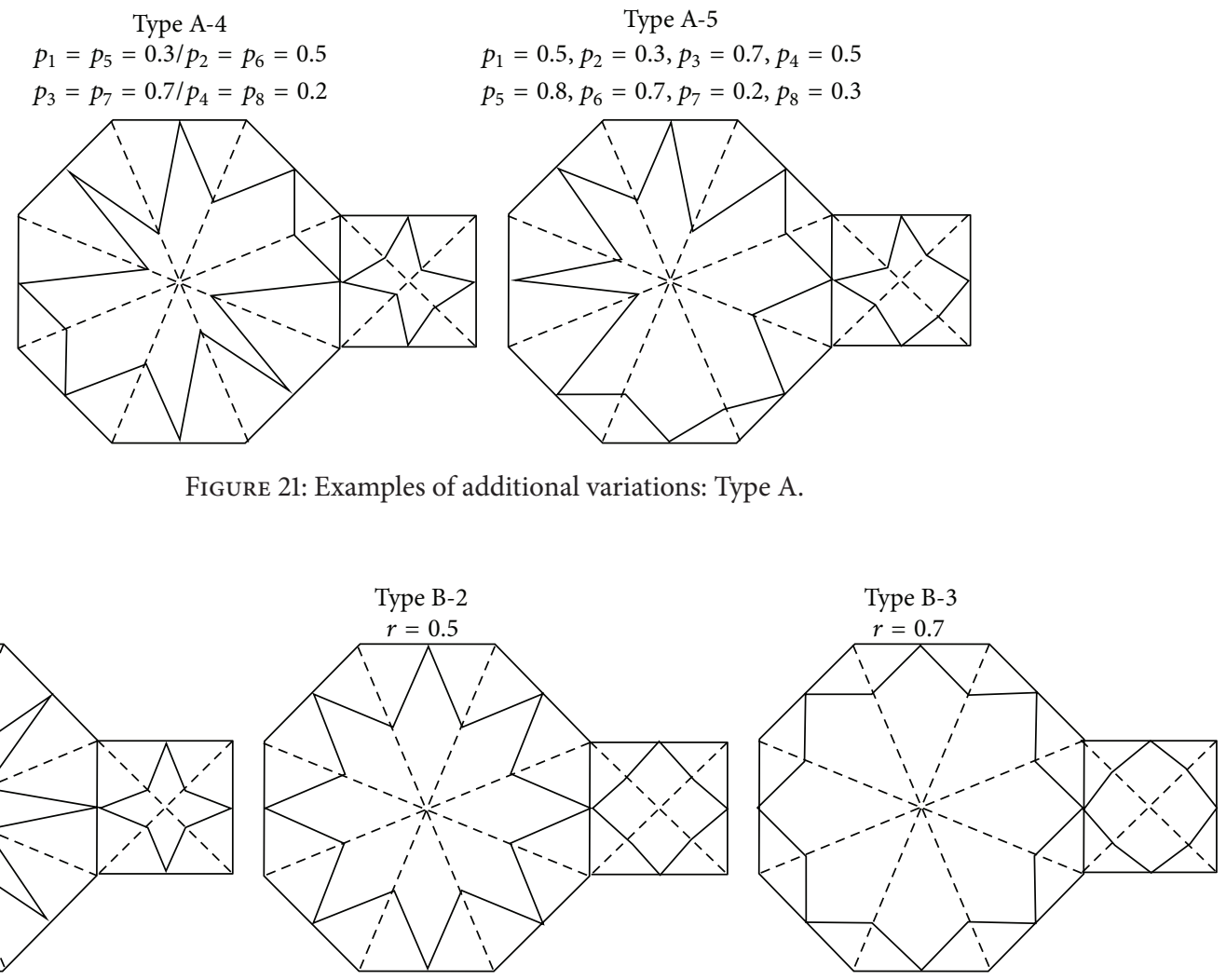

FIgURE 22: Examples of basic variations: Type B. 

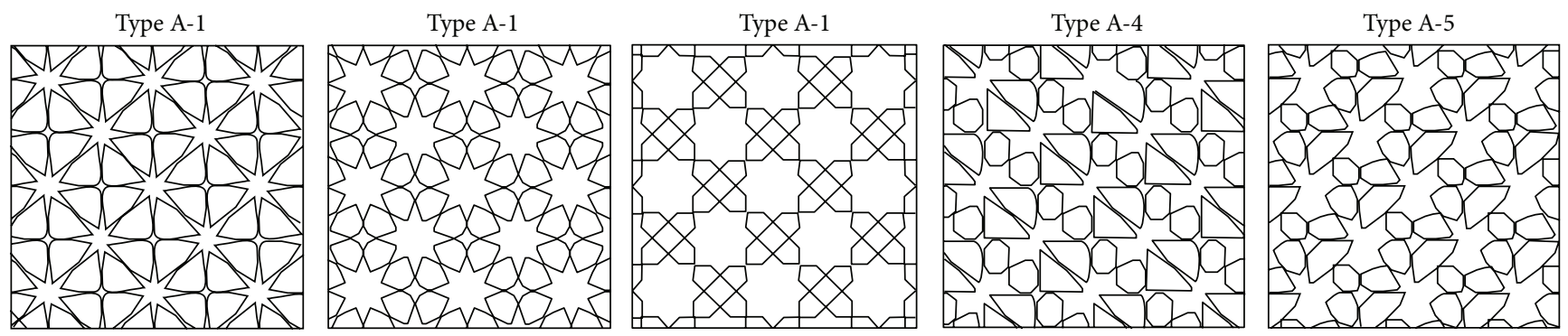

FIgURE 23: Type A patterning.
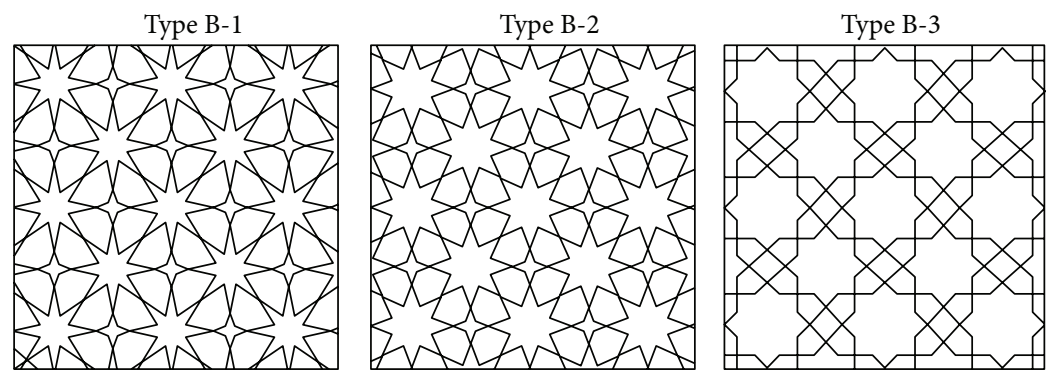

FIgURE 24: Type B patterning.

Single module expansion method

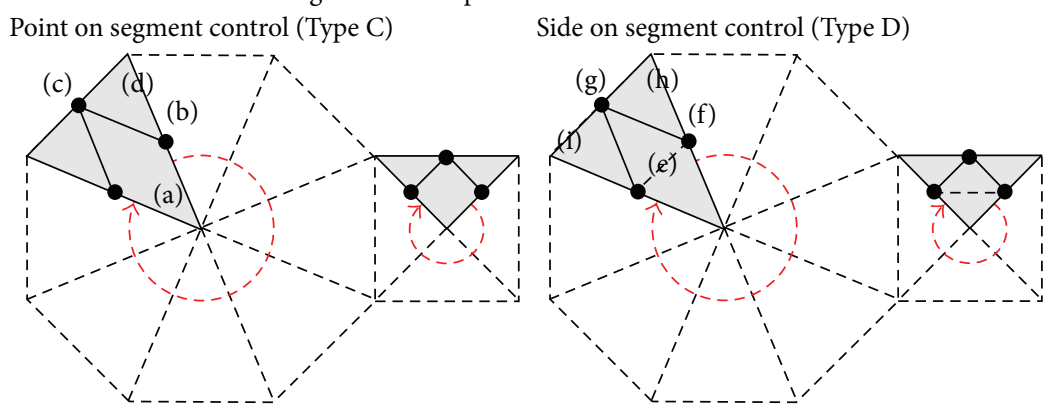

FiguRE 25: Single module expansion method diagram.
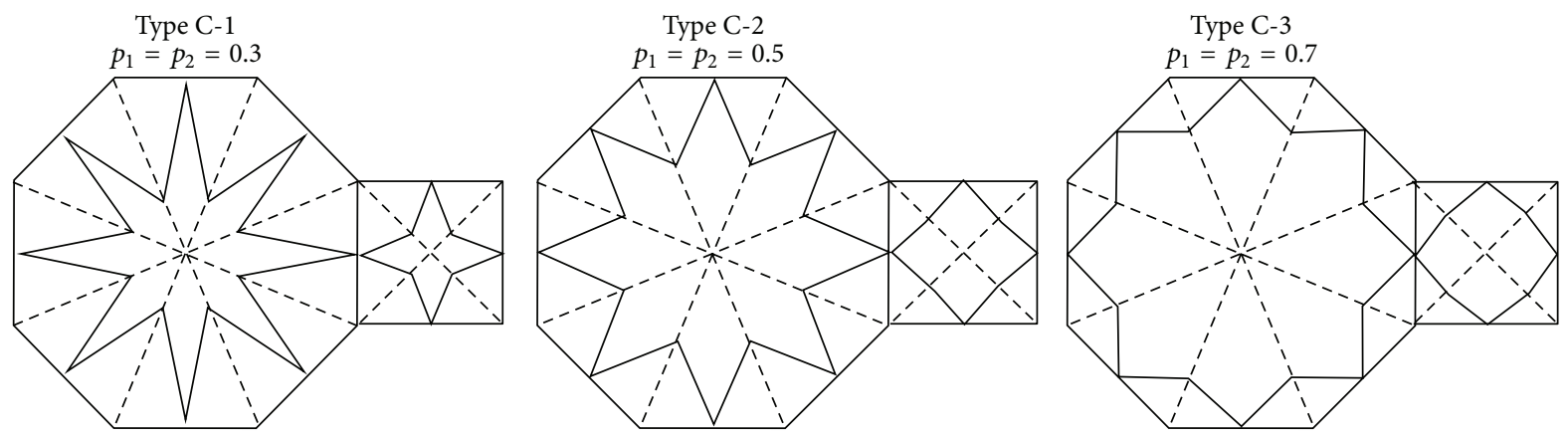

Figure 26: Examples of basic variations: Type C. 

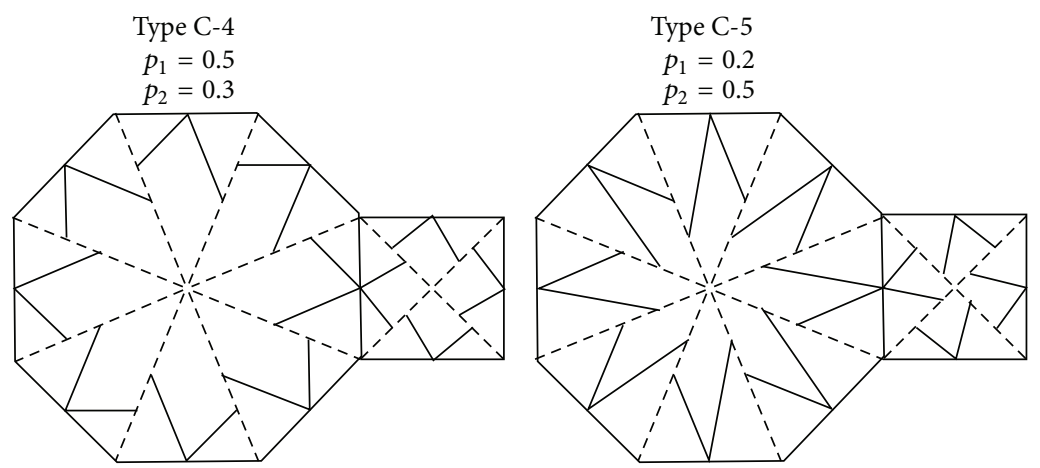

FIgURE 27: Examples of additional variations: Type C.
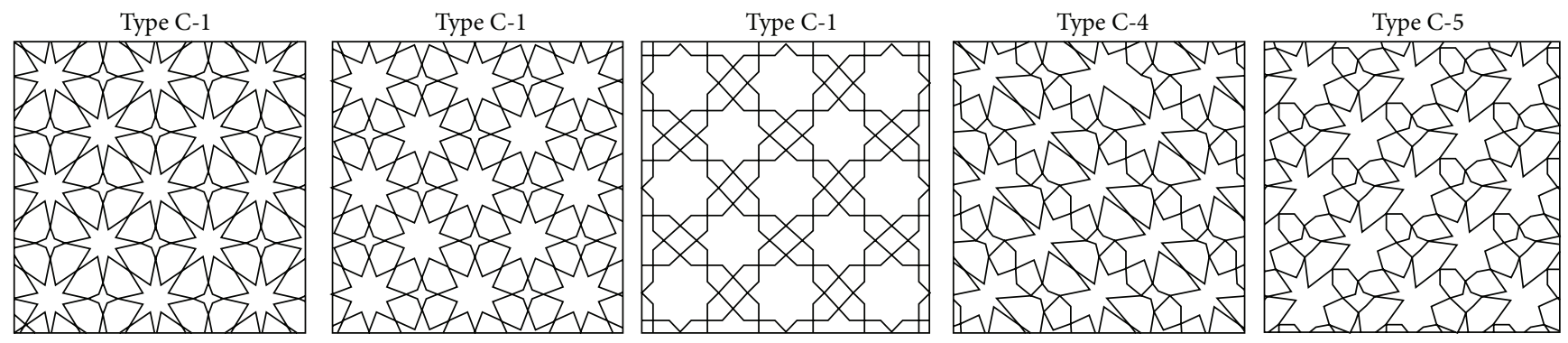

Figure 28: Type C patterning.

4.3.1. Side-Splitting Control Method. The side-splitting method can be divided into the point on side control and the radius control methods. In the point on side control method, a point on a segment (Figure 19(a)) connecting each angular point of an octagon with the middle point is set up as a variable. Therefore, if the point on the segment moves, the length of a line connecting point (a) on the segment with the middle point (Figure 19(b)) of each side of the octagon changes. In the radius control method, the radius $(r)$ of a circle, whose middle point is the middle of the octagon, and the segment, which connects each angular point of the octagon and the middle point, are set up as variables. Therefore, if the position of the cross-point (Figure 19(e)) of the circle and the segment (d) shifts, the length of the line that connects them changes as well.

(a) Point on Segment Control Method (Type A). The point on segment control is a method that controls the position of a point (Figure 13: $p$ ) on each vector segment (Figure 13: $d$ ) as a manipulative variable. Because the method can control the respective positions of points on vector segments $(0<d<$ $1)$, it can change the vector into various shapes. However, it requires a complex mathematical formula, because it has to analyze the position of each point on each segment. Because this method appoints the respective position of each point, it can set up each line with a different length. As a result, it can create modules of various shapes in an infinite number. If the critical point is not appointed, the position of a point can deviate from the segment; therefore, the critical point of the segment must be appointed.

If each point in Type A is controlled (Figure 13: $p_{1}-p_{8}$ ), additional modification is possible as a complement to basic modifications. If we control each of the eight points with the same value, we can create a star pattern with a regular shape (Figure 20: Types A-1 3). Conversely, if we control each point with a different value, we can create a random pattern (Figure 21: Types A-4 5).

(b) Radius Control (Type B). Radius control is a method that controls the radius value of a circle beginning from the middle point of an octagon as a manipulative variable (Figure 14: $r$ ). Once the value of the radius of a circle is set up, it is automatically connected to the cross-point with each vector segment. It is relatively easy to control and has a simple mathematical formula (Figure 22). However, in contrast to the points in the segment control method, additional modification is relatively difficult because the points are integrated by a circle. As with the radius control method, if the radius value $(r)$ is not appointed, the size of the circle can increase toward infinity, and the cross-point with a segment does not occur. Therefore, a critical point must be set up for the radius value $(r)$.

If two types of the side-splitting control method, Type $A$ and Type B, are combined, the patterns will be as follows (Figures 23 and 24). Types A-1 3 and Types B-1 3 have different control methods, but they create combinations of the 

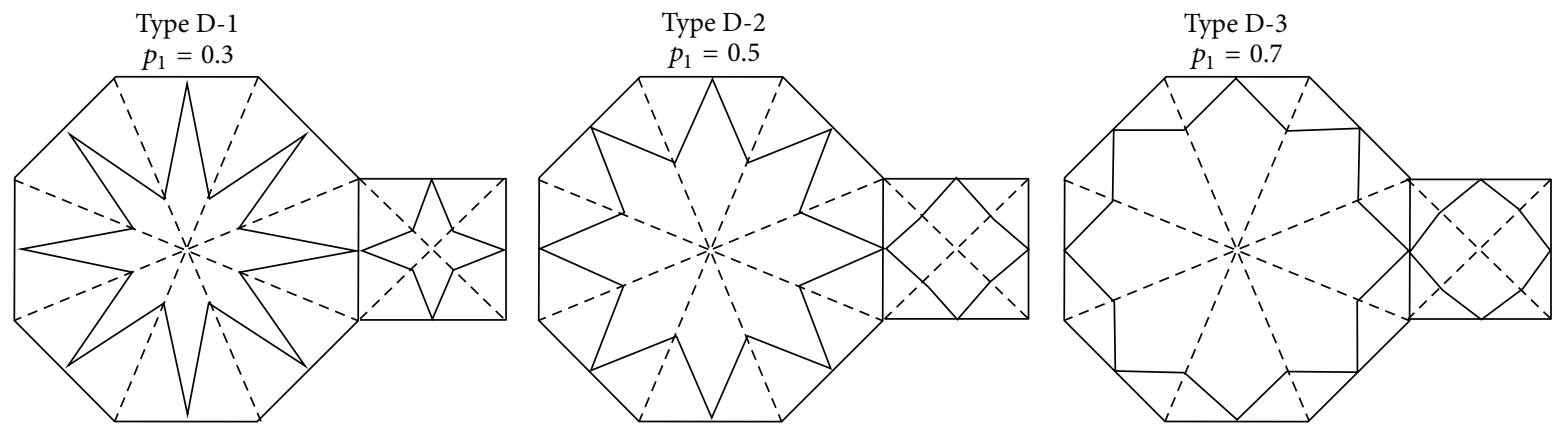

FIGURE 29: Examples of basic variations: Type D.
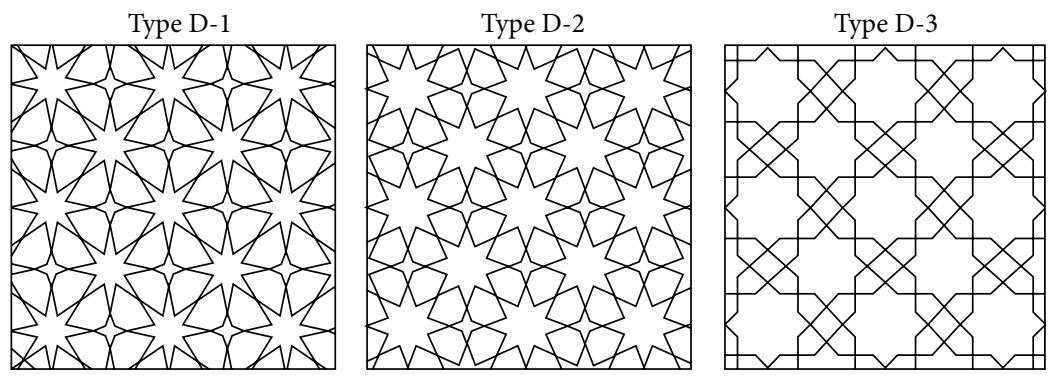

FIgURE 30: Type D patterning.

same shape. Also, Type A allows for additional modifications and can create different shapes in an infinite number, while additional modifications are difficult with Type B.

4.3.2. Single Module Expansion Method. The expansion of a single module can be divided into two methods: the point on segment control and the side on segment control. This method is based on the idea that an octagon can be divided into eight triangles of the same shape (Figure 25(a)). It is based on a concept that once one module of a triangle is controlled, it rotationally deforms the other modules by $45^{\circ}$. In the point on segment control method, a point on the segment (Figure 25(b)) which connects each angular point of the octagon with the middle point is set up as a variable. If the point on the segment shifts, the length of a line connecting the middle point of each side of the octagon (Figure 25(c)) with the point on the segment changes. However, in the side on segment control method, the segment (Figure 25(e)) where the bottom side (Figure 25(i)) of a triangle converges along both sides (Figure 25(h)) to the middle point is set up as a variable. If this segment (e) shifts, the length of the segment that connects the cross-point (f) of both sides (h) with the middle point ( $\mathrm{g}$ ) of the segment (i) changes.

(a) Point on Segment Control (Type C). The point on segment control is a method that constructs the expansion of a single module by controlling one of the triangles which forms an octagon. As this control method uses the position of a point (Figure 15: $p$ ) on each vector segment (Figure 15: $d$ ) as a manipulative variable, it has to analyze the position of a point on each vector segment and requires a complex mathematical formula. Compared to Type A, this method controls relatively fewer points, because it needs to control only two points. Thanks to this, it can designate each segment with a different length and create various module shapes. In this method, once one module is controlled, the others are automatically controlled due to the fixed angle. As single modules are combined to form an octagon, it is highly likely to construct an equilateral octagon.

Because Type C can control two points (Figure 15: $p_{1}$, $p_{2}$ ) simultaneously, it can create additional variations to complement basic modifications. If the two points are controlled with the same value, this can create a star pattern with a regular shape (Figure 26: Types C-1 3). If each point is controlled with a different value, it can create a random pattern (Figure 27: Types C-4 5). This becomes a module, creating rotational modification (Figure 28).

(b) Side on Segment Control (Type D). Similar to the point on segment control method, the side on segment control method constructs an octagon by controlling a single module, which is one of the triangles in an octagon, and by expanding a unit module (Figures 16, 29, and 30). However, unlike the segment control method, additional modifications are relatively difficult because the control is integrated to one side that moves above the vector segments on both sides.

4.4. Type-Specific Evaluation Analysis. This study will look into the Islamic star pattern formation of a geometric figure combination of 4.8.8, which appears in Hankin's method, depending on the four types of parameter control, and then will analyze the modification possibility and the convenience of algorithm designs of each of the four types of parameter control. 

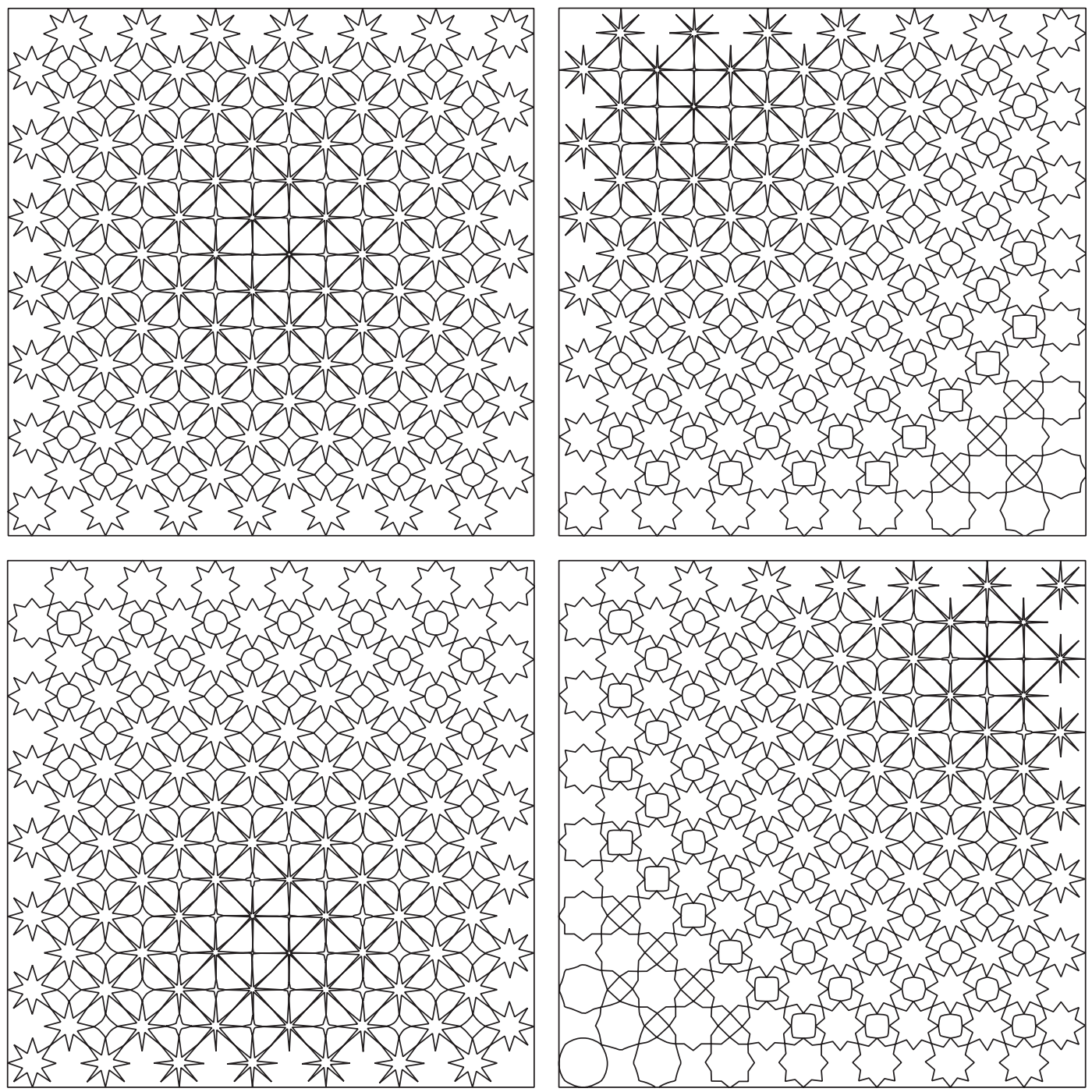

FIgURE 31: Pattern variations using Attractor Algorithm.

4.4.1. Modification Possibility. Modification possibility means how diversely a basic geometric figure can be modified. Basically, by appropriately controlling the parameter of each of the four types of parameter control, we can modify patterns into diverse shapes [Types A D-1 3]. However, whether additional modifications are possible or not will depend on whether the parameters are individually controlled or integrated. If the parameters are individually controlled [Type A, Type C], it is possible to modify them into other patterns. In contrast, if the parameters are integrated [Type B, Type D], it is relatively difficult to produce additional modifications.

4.4.2. Design Algorithm Convenience (Program Implementation Supremacy). In this paper, the convenience of design is analyzed from an algorithm perspective. In terms of the implementation of mathematical formula algorithms, if a program has a relatively simple mathematical formula and is convenient to control, implementation of the program is easy and its mathematical formula algorithm has an outstanding design convenience (Figure 31). The level of convenience of a mathematical formula algorithm is determined by whether the mathematical formula that controls the parameters is simple or complex. If the parameters are controlled individually, the mathematical formula becomes complex. If the parameters are integrated, the mathematical formula is relatively simple. Therefore, the design convenience for even the same shape of patterns can vary depending on whether parameters are controlled individually or are integrated. Among the four types of parameter control, the integrated method which controls only the radius value [Type B] has the simplest mathematical algorithm and therefore a high design convenience. The method which has to control each individual parameter [Type A] has the highest modification possibility, but a low design convenience because of the relatively complex mathematical algorithm (Table 1).

\subsubsection{Subconclusion. See Table 1.}




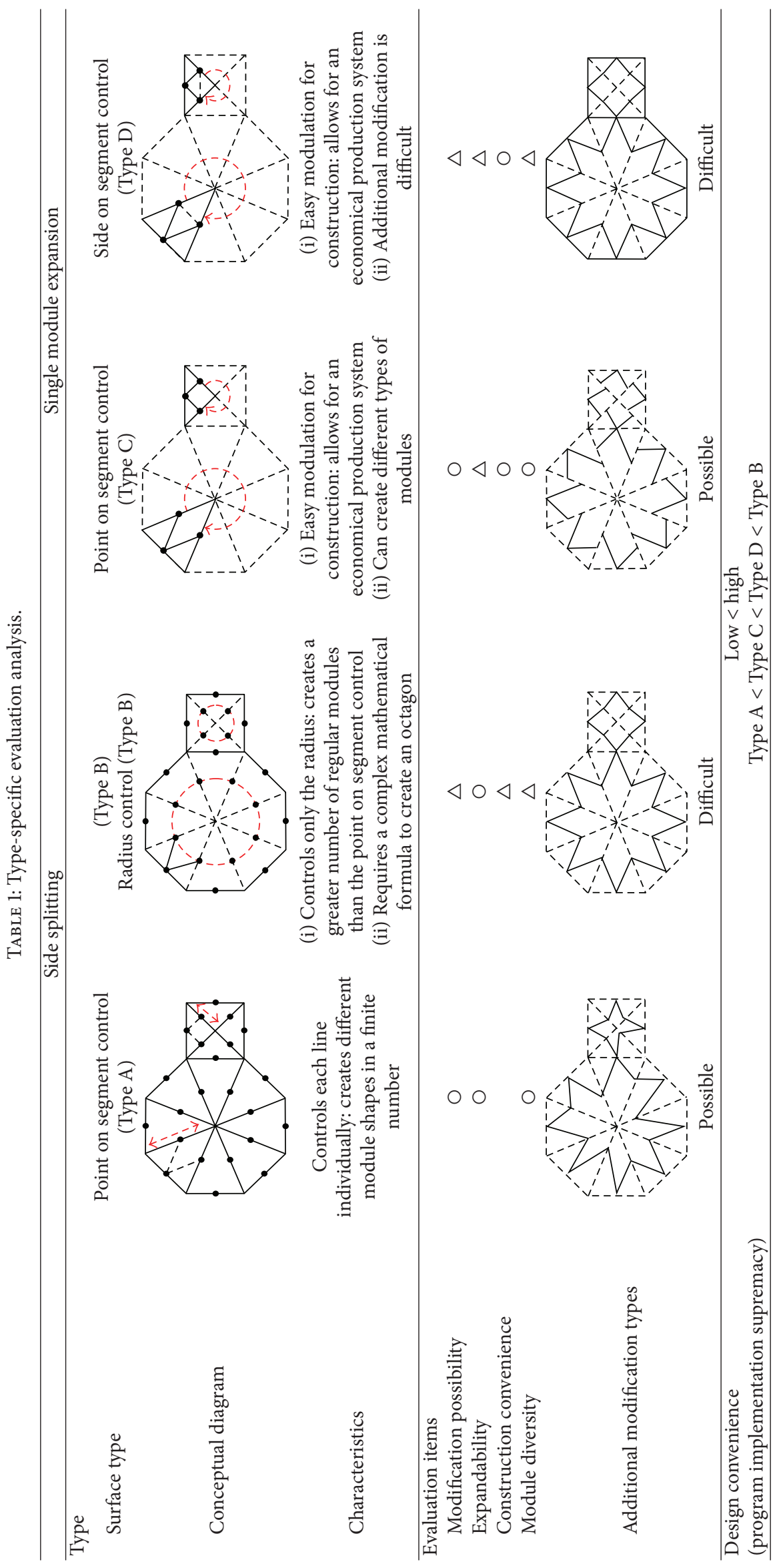




\section{Conclusion}

This study aims to analyze and modify the Islamic star pattern using digital algorithm, introducing a method to efficiently modify and control classical geometric patterns through experiments and applications of computer algorithm. This study reveals that with the help of algorithmic design strategy we can analyze and undermine the rigidity of the classical geometry of Islamic star pattern and expand its design potentials. Clear understandings of the classical geometry and proper experiments with digital algorithm can contribute to overcoming the gap between the classical geometry and the digital technology and to laying out a solid foundation for efficiency and flexibility in developing future designs and material fabrication.

\section{Conflict of Interests}

The authors declare that there is no conflict of interests regarding the publication of this paper.

\section{Acknowledgment}

This paper was supported by the National Research Foundation of Korea no. NRF-2013R1A1A2058553.

\section{References}

[1] B. Gruenbaum and G. Shephard, Tilings and Patterns, W.H. Freeman, 1989.

[2] D. Seymour and J. Britton, Introduction to Tessellation, Seymour Publications, 1989.

[3] J. Yoo, A Study on the Application of Spatial Configuration to Escher's Oppositive Tessellation, Kunkook University, 2009.

[4] R. Tennant, "Medieval islamic architecture, quasicrystals, and Penrose and girih tiles: questions from the classroom," Symmetry: Culture and Science, vol. 19, no. 2-3, pp. 113-125, 2008.

[5] N. Yanofsky, "Towards a definition of an algorithm," Journal of Logic and Computation, vol. 21, no. 2, pp. 253-286, 2010.

[6] Y. Choi and J. Kim, "A study on image construction of skin based on expandable patternization process," Journal of Korean Institute of Interior Design, vol. 17, no. 2, pp. 30-38, 2008.

[7] A. A. Yassine, "Parametric design adaptation for competitive products," Journal of Intelligent Manufacturing, vol. 23, no. 3, pp. 541-559, 2012.

[8] M. Stavric and O. Manna, "Parametric modeling for advanced architecture," International Journal of Mathematics and Informatics, vol. 5, no. 1, pp. 9-16, 2011.

[9] Y. Abdullahi and M. R. Embi, "Evolution of Islamic geometric patterns," Frontiers of Architectural Research, vol. 2, no. 2, pp. 243-251, 2013.

[10] L. M. Dabbour, "Geometric proportions: the underlying structure of design process for Islamic geometric patterns," Frontiers of Architectural Research, vol. 1, no. 4, pp. 380-391, 2012.

[11] C. Kaplan, Islamic Star Patterns from Polygons in Contact, University of Waterloo, 2005. 

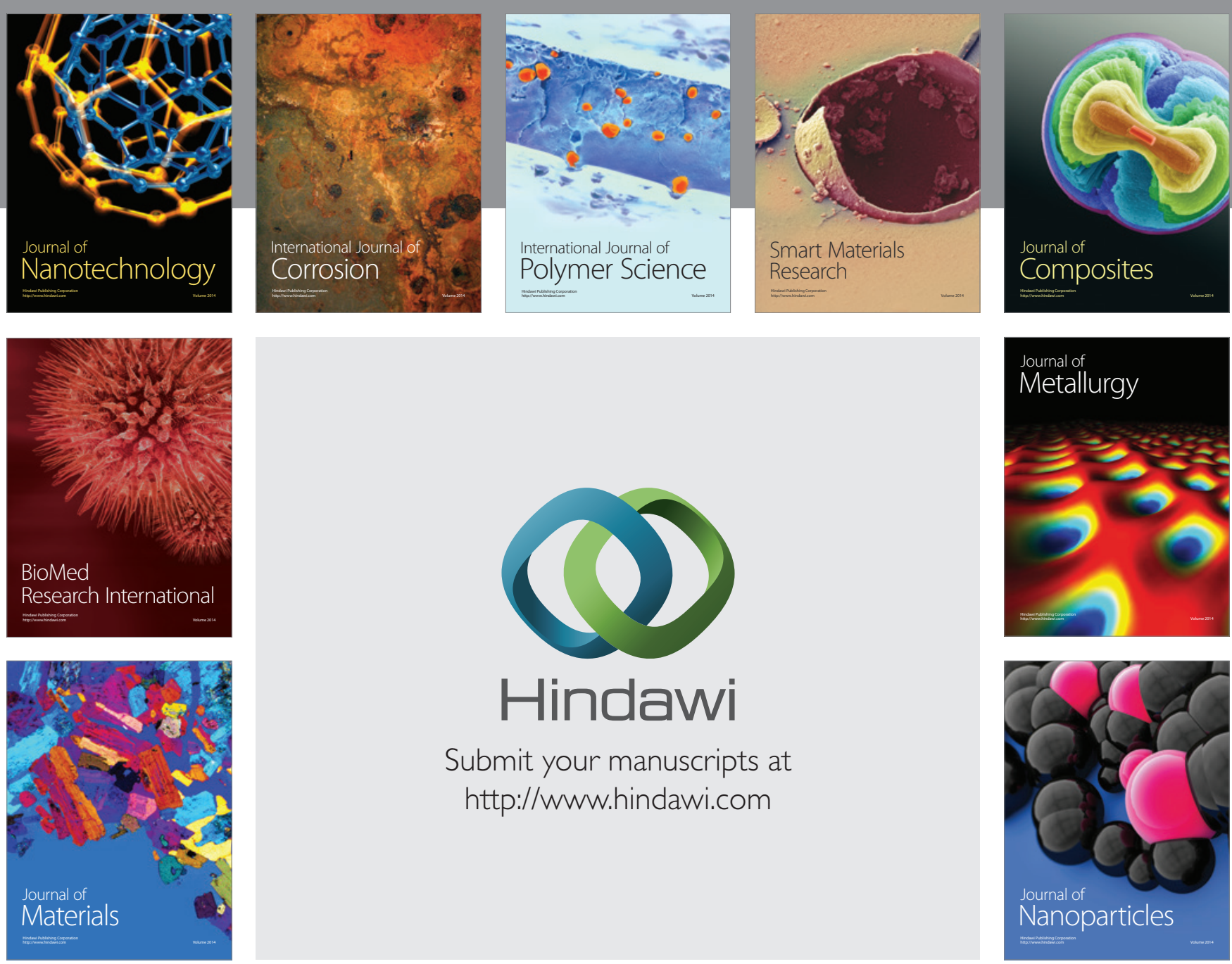

Submit your manuscripts at http://www.hindawi.com
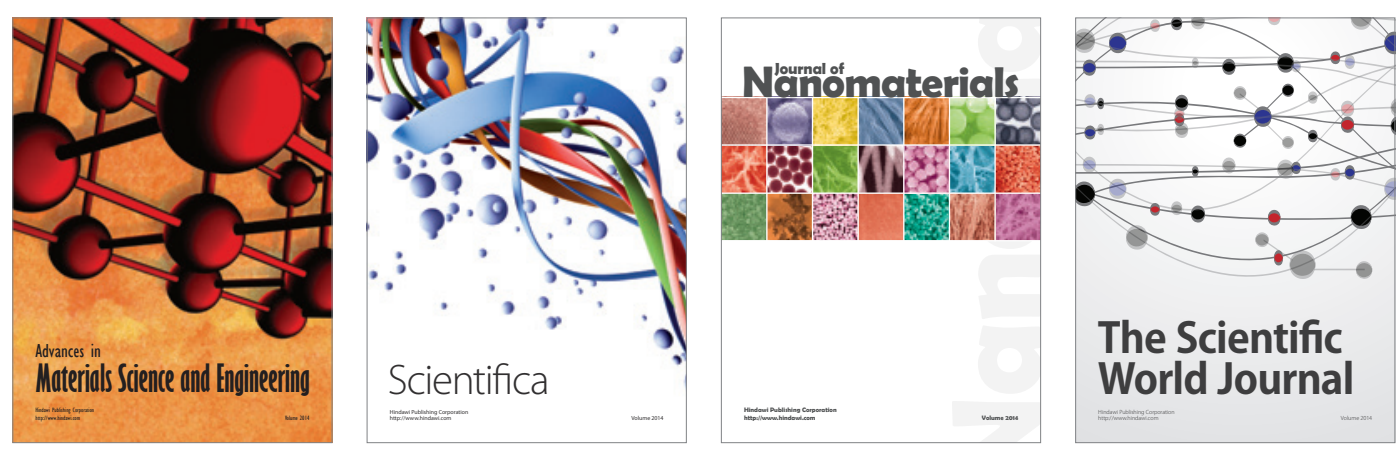

\section{The Scientific World Journal}
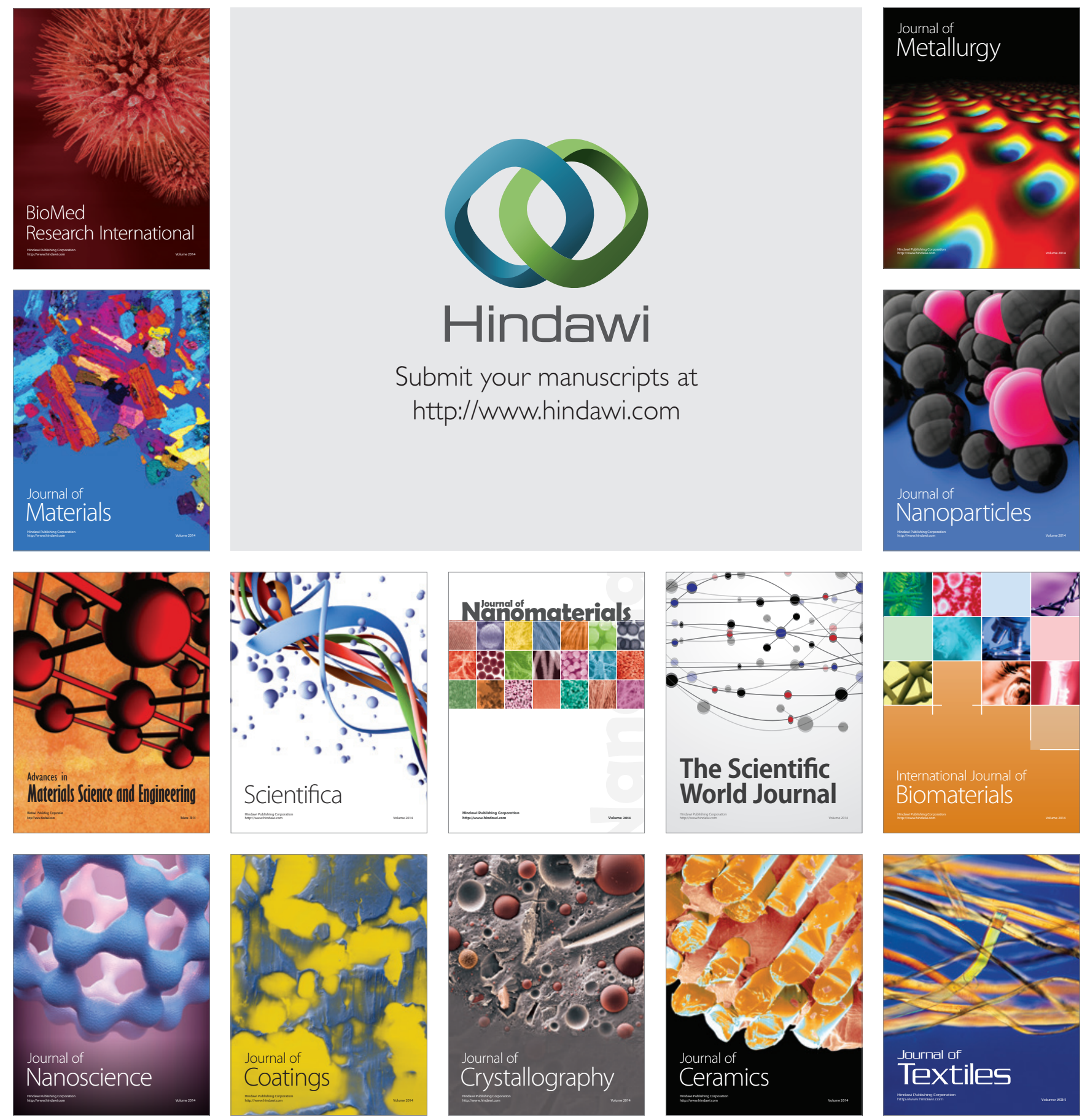